\section{A CASE OF EXOPHTHALMIC GOITRE, ENDING FATALLY FROM SUDDEN PRESSURE ON THE TRACHEA.}

By Hugh Montgomerie, M.D., ASSISTANT PHYSICIAN, WEST CORNWALL INFIRMARY, PENZANCE.

Through the kindness of Dr. Humphry Davy I am able to record this case, which, so far as my researches extend, seems to be unique.

In March last I saw the patient, Mrs. X-, aged thirtyfive, who complained of a swelling in the neck, nervousness, slight difficulty of breathing, with stridor and cough. She stated she was pregnant. Her own health and family history were good. Her neck, she informed me, had been swollen for two years (I since hear it was longer), and measured twenty-three inches in circumference. The swelling consisted in a softish elastic mass, larger on the left side than the right, and with a small central mass. There was no doubt the swelling was a bronchocele. The eyes showed some exophthalmia and dilated pupils; Von Graefe's sign present to a slight extent; there was no tremor. The pulse was 120 . The larynx showed nothing abnormal, but it was impossible to see below the cords with the laryngoscope. From her condition and the deep origin of the growth no interference was recommended. In September, 1890, I had another opportunity of examining her after delivery, and found the symptoms abated, the neck only measuring twenty-one inches in circumference. In the early morning of December 1st, 1890, I was called to the patient's house, and found her lying on a bed unconscious, breathing rapidly and with considerable stridor, the lips and face cyanosed. Dr. Davy, Mr. Symons, and myself were sent for. We learnt that at half-past ten the previous night she had gone to bed quite well. In about an hour she got up to attend to the baby, and was seized with severe difficulty of breathing. She got back to bed, struggled violently, and became unconscious in the course of five minutes. Tracheotomy was determined on, though the patient was evidently moribund. The tube was inserted by Dr. Davy, who performed the low operation. There was scarcely any bleeding during the operation. One inspiration was taken through the tube, and artificial respiration resorted to without avail.

A necropsy was granted, which I performed in the afternoon. It was then found that the right lobe of the thyroid was attached to the trachea firmly, and the size of an egg. The left lobe about double the size, and implicating the deep structures of the neck. The isthmus was much enlarged, and a supplementary lobe of the gland lay on the thyroid cartilage. On removing the larynx, trachea, and thyroid gland, one saw on looking up the trachea that the right wall was bulged in towards the left, leaving only a mere chink to breathe through. The bulging corresponded with the right lobe of the thyroid gland. On splitting up the trachea, the cartilages at the obstruction were softened, and had lost all their resiliency, thus aiding the collapse of the tube. The mucous membrane was injected.

I have considered this case worthy of record, as showing that, although the cartilages of the trachea had been softening for some time, the actual "caving in" was in the end quite sudden.

Penzance.

\section{A CASE OF TETANUS; RECOVERY.}

BY A. C. DutT, B.A., M.B. Cantab., A.K.C. Lond., SENIOR HOUSE SURGEON TO THE SCARBOROUGH HOSPITAL.

ON the 22nd September James $\mathbf{A}$ - , aged thirty-five, a fisherman belonging to Peel, Isle of Man, was admitted under the care of Dr. Everley Taylor, suffering from wellmarked symptoms of tetanus. In August last his left hand was crushed between two boats, producing a wound three inches long at the level of the heads of the second and third metacarpal bones. For this he was treated as an in-patient at the Berwick-on-Tweed Infirmary for five weeks, and left that institution (with the wound not quite healed) to join his boat. He fished off Hartlepool for some days, whence he came to Scarborough and sought admission here. On inquiry the patient admitted he had indulged freely in alcohol, and had syphilis about twenty years ago. On one leg there was a fetid tertiary ulcer, and on both legs there were several pigmented cicatrices. He was unmarried. Patient said that when he was off Hartlepool he had pain in the back of his neck, and then the " jaws began to contract"; the legs felt very stiff, and he found he could not swallow. On examination it was found that he could not separate his teeth more than a quarter of an inch; there was a very peculiar anxious look, and the masseters and the recti abdominis were extremely rigid. The wound on the hand was covered with small unhealthy granulations, and was very foul smelling. Before he came into the hospital he had taken lodgings in the town, where Dr. Everley Taylor had seen him in a state of opisthotonos. His temperature on admission was $98 \cdot 6^{\circ}$, and was never above normal throughout the course of the disease. He was ordered a mixture of ten minims of the tincture of cannabis indica, fifteen grains of chloral and bromide of sodium, five minims of chloric ether, with mucilage and water, every four hours. As to diet, he had three pints of peptonised milk, two pints of beef-tea, two eggs, six ounces of brandy, and six ounces of port wine daily. The wound on the hand was dressed with starch poultices for the first fortnight, and then with boracic oint ment; the ulcer on the leg was also washed and dressed. The patient complained of "spasms," but steadily improved under the treatment. After Oct. 3rd stimulants were reduced to two ounces each of port wine and brandy daily; minced meat and bread were given on the 7 th. On the 15 th, pills of Calabar bean, one-sixth of a grain (gradually in. creased to half a grain) three times a day, were ordered. The patient could sit up on the 10 th, and had full diet on the 19th. On the 20 th the wound on the hand had quite cica. trised, and the patient was discharged on Nov. lst.

Remarks. - Of late the theory has been gaining ground that tetanus is of microbic origin, and that the microbes produce an alkaloid which acts on the nervous system. The fact that division of the injured nerve at the seat of injury has sometimes been found curative does not necessarily disprove this theory, for doubtless with the division of the nerve precautions are taken to render the wound aseptic, so as to prevent the development of the microbes. The absence of any definite lesions in fatal cases also lends support to this view. According to Dr. George Kemp, there are three essential okjects to be attained in the treatment- $(a)$ The"destruc. tion of the nidus of development of the bacilli ; $(b)$ the elimination from the system of the products of the bacilli; and $(c)$ the calming of the nervous system. Scarborough.

\section{SPONTANEOUS AMPUTATION OF THE SMALI} TOE IN AFRICANS.

BY J. ToppIN, L. K.C.S.I., L. \& L.M. K.Q.C.P.

Although doubtless this anomaly has been observed by Englishmen who have visited Africa, it has not hitherto, to the best of my belief, been described in the medical press. It seems, as far as I am aware of, only to occur amongst Africans ; although I have never seen it in those inhabiting the West India islands, I believe it is common enough in Brazil amongst the negroes. The cases I have met with were among Kroomen, who come from a part of the West Coast of Africa about a day's journey from Sierra Leone. These men seldom wear boots, and consequently have very well shaped feet. The affection commences by a crack ap. pearing on the under and inner surface of the little toe; a thing which is frequently met with amongst soldiers of whatever nationality, and which English sailors designate by a name more expressive than elegant. It, however, never goes beyond a crack or fissure in Europeans ; but with Africans, whether living on shore away from the sea or on board ship, there is a progressive process, resulting ultimately in the toe dropping off. It is in no way connected with leprosy; the little toe is nearly always the only one affected, though the natives tell me that in rare cases the fourth toe goes also. I have tried incising the fissure, and then dressing it and making them wear boots to keep out the salt water but all to no purpose. The process when once commenced goes on, the fissure gradually extending round the toe. I have never allowed it to proceed to complete loss of the toe, because after a few months there is considerable pain with some cedema of the foot, and in order to render the man able to work I have taken the toe off. In their own country, however, not having a surgeon at their service, 
they have to let it run its course, and it then takes about a twelvemonth before it finally drops off. The appearance when the fissure has extended completely round the toe is exactly as if a ligature had been bound tightly round it, as near its junction with the foot as possible. The extensor tendon can be seen as a white cord marked with a black ring where the fissure crosses it In two cases where I have removed the toe, the joint of the ungual phalanx was wanting. The wound heals quickly after removal, and the men do not seem to feel the loss of the toe in the slightest. Pernambuco, Brazil.

\section{TRAUMATIC ENCEPHALO MENINGOCELE.}

BY Harry Burton, M.R.C.S., L.R.C.P. IrEL., \&c

Having used the above title for a case I reported in THE LANCET of Jan. 10th, and having read a note in the same journal of Jan. 17th by $\mathrm{Mr}$. Clement Lucas objecting to the name, I wish to give the following reasons for having done so.

According to Messrs. Clement Lucas and Golding Bird traumatic cephal-hydrocele can only be developed in early childhood, and is caused by cerebro-spinal fluid extravasated under the healthy in teguments, through a fissure or fracture of the skull, such fluid communicating with the ventricles through the perforated meninges and brain. In the case mentioned by me, the girl was eight years old; the fracture was at first compound, the skin wound healed, absorption of a necrosed circular portion of the skull occurred, and the meninges and brain substance were gradually protruded through the opening. I do not think the fluid communicated with the ventricles, but was simply increased inflammatory secretion, as after aspiration the tension became less, and (which was not the case before) pressure could be borne. I also explained that on withdrawal of the needle, which was not inserted to the base of the tumour, brain substance appeared on it. The tumour also was only partially emptied, which proves that its contents were not altogether fluid. I quite agree with Mr. Lucas that traumatic cephal-hydrocele is a better name for the cases he has published than traumatic meningocele, as only fluid could come through a crack in the skull, the absorption of bone being secondary, and therefore no meninges are contained in the swelling at all ; but I must say, with all deference to him, that the case I described differs so much in all its salient points that the above title only thoroughly conveys a right idea of its com. position. I may again state that there is no sign of any tumour remaining, no heaped-up or everted edges of bone, the skin being perfectly level, the circular opening in the bone almost filled with dense fibrous tissue, and that the girl is in good health at the present time.

Marple.

\section{9 attiruor}

\section{HOSPITAL PRACTICE, BRITISH AND FOREIGN.}

Nulla autem est alia pro certo noscendi via, nisi quamplurimas et morborum et dissectionum historias, tum aliorum tum proprias collectas habere, et inter se comparare.-MORGaGNI De Sed. et Caus. Morb., iib. iv. Proœmium.

\section{CHARING-CROSS HOSPITAL.}

A CASE OF AURAL POLYPUS ACCOMPANIED WITH MASTOID SUPPURATION AND THREATENING THROMBOSIS OF THE LATERAL SINUS; PERFORATION OF THE MASTOID CELLS; REMOVAL OF THE POLYPUS; CURE.

(Under the care of Mr. MARMADuke Sheid.

THE attention of the profession has been frequently directed, more especially during recent years, to the dangers of a chronic discharge from the middle ear. Such cases, where treatment has been neglected, are not uncommonly admitted to our hospitals for mastoiditis or even mor serious consequences secondary to the discharge, especially if it is decomposing and its escape is impeded, as in this instance, by the presence of a polypoid growth. Great in. provementin our knowledge of the pathology of the inflammatory affections of the mastoid process has resulted fro an more careful study, and we recognise that there are in snch affections especial dangers from the proximity of vital structures. One direction in which inflammation may extend is through the petro-mastoid canal into the cranial cavity, or it may involve further the transverse sinus and cause thrombosis, and symptoms of the commencement of this condition were present in this case. The fatal termination of a purulent otitis media may be due to many causes-phlebitis, thrombosis, embolism, septicemia, pyæmia, purulent meningitis, intra cranial abscess, \&c. - any one of which may be excited by apparently accidental circumstances. In all these the chance of life is small without operative treatment, and in few can such success be obtained, both as regards arrest of symptoms and restoration of function, as in the case which we record.

A healthy-looking young man was admitted into Charingcross Hospital on Dec. 3rd, 1890, under the care of Di. Green. He was supposed to be suffering from some cerebral disease. A fetid discharge being found to issue from the right ear, the patient was transferred to the surgical wards. The leading symptoms observed were as follows: Great tenderness over the side of the head and mastoid region, but no obviously tender spot or cedema. Marked tenderness also over the course of the internal jugular vein on the right side of the neck, but no hardness. There was no evidence of lung complication. Profuse fetid discharge issued from the right ear. On washing this away a large, vascular, friable polypus, of the colour of a ripe raspberry, was seen to fill the auditory canal. The patient was absolutely deaf upon the right side, and could not hear when shouted at. A large tuning.fork placed upon the vertex was heard most plainly on the affected side. The left ear seemed normal. The patient was somewhat drowsy and stupid, but answered questions fairly well. There was no optic neuritis. The pulse was quick, hard, and full, the tongue very fool, and the bowels constipated, but the temperature was not high. A reliable history was difficult to elucidate. It appeared that he had suffered from right otorrhcea for an indefinite period. For the last few days he had had intense pain in the head, so severe as to cause him to cry out and entirely to prevent sleep. He has felt giddy, and was sick several times at the commencement of the attack.

It was resolved to open the mastoid cells, and this proceeding was sanctioned by Mr. Bloxam, who kindly saw the case in consultation. The operation was performed at 5 P.M. on the same evening. The side of the head being shaved and rendered aseptic, a free vertical incision was made by $\mathrm{Mr}$. Sheild over the right mastoid, and the soft parts and periosteum were turned back from the bone on either side. An opening was then made immediately behind the upper margin of the external auditory meatus, by means of a small sharp gouge and mallet. The bone was exceedingly dense and hard, and the opening was cautiously deepened to a depth of rearly one-eighth of an inch before a blunt director passed into the mastoid cells. Very free bleeding occurred as soon as the cells were opened, the blood welling out in a continuous stream, as though some large vessel har been wounded. A strong syringe filled with hot boracic lotion was applied to the aperture, and blood mixed with a quantity of thick pus and masses of débris escaped from the auditory meatus. The bleeding soon spontaneously ceased. The polypus was next removed by a pair of ring forceps, and the incision behind the ear united with horsebair, a drainagetube being inserted into the opening made in the bone. The parts were dressed with iodoform and sal alembroth gauze. After the operation the patient lost all pain and disagreeable sensations in the head and side of the neck. He made an uninterrupted recovery. The wound united soundly, and the tube was removed on the fifth day. The after-treatment consisted in washing through the mastoid with warm boracic fluid and the application on three occasions of pure chromic acid to the remains of the polypus. The latter had grown from the interior of the tympanum through a large perforation in the membrana tympani. By the fifth day he could hear the watch at three inches and conversation fairly well. Treatment was now directed towards the perforation. Under simple syringing with warm boracic fluid and cleansing of the ear afterwards with wool this closed in about three weeks.

A wonth after the operation the patient was carefully examined. All discharge had ceased, and the chasm had 